\title{
RISK ASSESSMENT OF TUNNEL PORTALS IN THE CONSTRUCTION STAGE BASED ON FUZZY ANALYTIC HIERARCHY PROCESS
}

\section{Xianghui Deng ${ }^{1} \quad$ Rui Wang ${ }^{2} \quad$ Tian $\mathrm{Xu}^{3}$}

This study presents a fuzzy analytic hierarchy process (FAHP) by integrating analytic hierarchy process (AHP) and fuzzy cognition to evaluate the construction risks of tunnel portals. Wuguanyi Tunnel is taken as the research objective to validate the performance of the proposed method. The result shows that the proposed decision making method can effectively identify risk factors and determine the risk level during the construction of tunnel portals. Finally, the corresponding control measures during the construction of the Wuguanyi Tunnel portal are proposed according to the risk assessment results.

Key words: tunnel portal; construction stage; FAHP; risk assessment

\footnotetext{
${ }^{1}$ Associate professor. School of Civil and Architecture Engineering, Xi'an Technological University, Xi'an, China, E-mail: xianghuideng@xatu.edu.cn

${ }^{2}$ School of Civil and Architecture Engineering, Xi'an Technological University, Xi'an, China, E-mail: wangrui@xatu.edu.cn

${ }^{3}$ School of Civil and Architecture Engineering, Xi'an Technological University, Xi'an, China, E-mail: 15249272511@163.com
} 


\section{INTRODUCTION}

With the rapid development of the Chinese economy and the increasing investment in the construction of infrastructure facilities in recent years, mountain highways have been developing quickly all over the country. As a result, tunnels are widely employed today in traversing mountains. In the last decade, tunnel construction has become the first choice for highway alignment because of its advantages of optimal alignment, shortened mileage, saved travelling time and enhanced operation efficiency. In fact, China has already become the country with the most highway tunnels and the longest highway tunnel mileages $[1,2]$. Compared with the overall length of a tunnel, portals usually have a limited area of influence; the construction of a tunnel portal is often difficult and easily leads to engineering accidents [3]. Major factors that increase the risk of accidents in tunnel portals may include the topography, geological and geotechnical properties of the rock mass and soil; rainfalls and underground waters; and construction methods. Since the influencing factors are diverse, complex and uncertain, which make the tunnels prone to slope instability, large deformation, tunnel collapse and others during the construction of tunnel portals, the lack of risk assessment and management may increase economic costs, prolong the time period allotted for a project and even cause fatal accidents [4]. Hence, risk assessment of tunnel portals during construction is necessary to manage and respond to the associated risks [5].

Risk assessment usually consists of two components: correctly identifying risk factors and evaluating the risk level. Obviously, risk factor identification is the first step and the basis of the process of risk management [6]. In fact, many risk factors lead to risk accidents, such as portal collapse, large deformation and instability of the tunnel face, during the construction of tunnel portals. However, identifying risk factors is very difficult. Firstly, different tunnels have different topographic conditions, geological conditions, construction methods and other features. In addition, the conditions may change as the tunnel is being excavated. For example, rainfall generally softens the surrounding rock of tunnel portals, which may increase the probability of accidents. Ensuring low risk levels is the most crucial and the most complicated portion of risk evaluation. It can offer some optimistic design parameters and a better construction method to reduce risk loss and to avoid risks according to the evaluation result. Risk assessment for tunnel portals during the construction stage has been widely recognised as one of the most 
critical phases. However, the influencing factors (such as the topography, geology of rock masses and underground water) at this stage are complex and uncertain. In most cases, complexity and uncertainty are dealt with difficulty, only depending on experts' judgments. How to handle the vagueness and subjectivity becomes a critical issue [7].

At present, some risk assessment methods have been widely used in the mining, nuclear, petrochemical and construction industries, including analytic hierarchy process (AHP) $[8,9]$, preliminary hazards analysis (PHA) [10] and fault modes and effects analysis (FMEA) [11]. AHP is a common method dealing with widely used the risk assessment, influenced by the subject during the establishment of the hierarchical structure and the judgment matrix. However, Triantaphyllou and Lakoff $[12,13]$ pointed out the weakness of AHP in assessing the relative importance of weights of various criteria. This weakness is caused primarily by two limitations. The first is the difficulty of using Saaty's discrete 9value scale to reflect the belief of decision makers in the relative importance relationships among the various criteria. The second is the difficulty of identifying the in-between numbers of fuzzy sets. In fact, some researchers have thought that making the judgments fuzzy is better when dealing with decisions in complex and uncertain environments $[14,15]$. They think that the 1-9 fundamental scale of the AHP is a scale of crisp numbers and thus is resolved to fuzzily these numbers [16]. They assume that by using fuzzy judgments (e.g. triangular, trapezoidal, interval and fuzzy numbers) instead of the usual 1-9 fundamental scale in making pairwise comparisons offers a better decision model [17]. Therefore, the authors take for granted the fact that they need to fuzzily the judgments to make applications with greater validity.

In this study, identifying the importance of risk factors and risk levels is difficult because the influencing factors during the construction of the tunnel portal are complex and uncertain. On the basis of the abovementioned analysis, FAHP combined with AHP and fuzzy mathematics is used to solve the problem above. Thus, the method has the advantages of AHP and fuzzy mathematics' comprehensive evaluation and overcomes the weakness of subjectivity in fuzzy comprehensive evaluation [18].

\section{FUZZY HIERARCHY EVALUATION THEORY}

Fuzzy hierarchy evaluation is a synthetic risk evaluation method based on AHP and fuzzy comprehensive evaluation [19, 20]. Firstly, the factor set and evaluation set are established by the fuzzy comprehensive evaluation method. Secondly, AHP or expert investigation method is used to calculate 
the weight values of each evaluation factor of the evaluation object (this study adopts AHP). Thirdly, expert investigation method is used to generate the judgment matrix, and then the object is evaluated through the fuzzy algorithm. The procedure for fuzzy hierarchy evaluation is shown in Fig. 1. The details are discussed as follows.

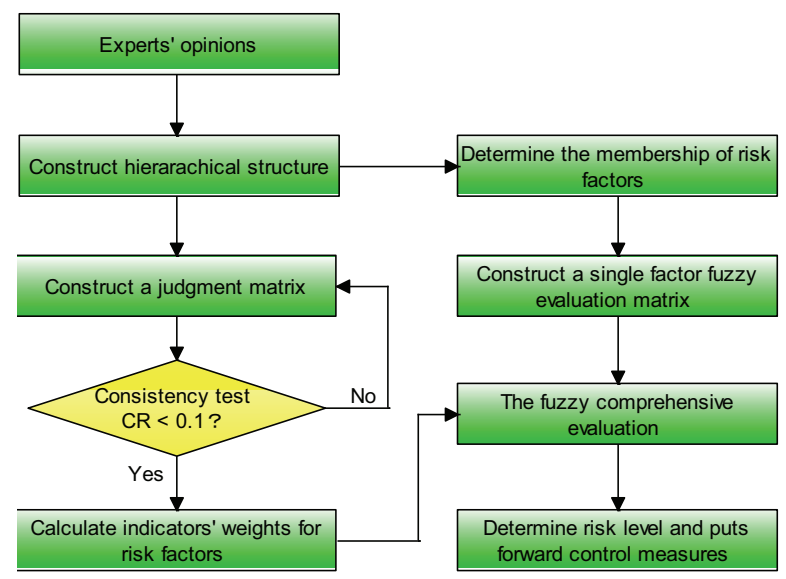

Fig. 1. Flow diagram of the proposed method

Step 1: Factor set

The factor set is composed of influencing factors $u_{i}(i=1,2, \cdots, n)$, which have effects on the evaluation object, expressed by $U$.

$$
U=\left\{u_{1}, u_{2}, \cdots, u_{n}\right\}
$$

Step 2: Evaluation set

The evaluation set is composed of various of the evaluation results $v_{i}(i=1,2, \cdots, m)$ made by the evaluator, expressed by $V$.

$$
V=\left\{v_{1}, v_{2}, \cdots, v_{m}\right\}
$$

Step 3: Ensuring weight

The relative weight of each influencing factor can be calculated by AHP. According to the hierarchical model and many opinions of authoritative experts, two evaluation indices are compared, and we can certify the relative importance of the evaluation object and the relative values. The weight of 
influencing factors is $W=\left\{w_{1}, w_{2}, \cdots, w_{n}\right\}$. In addition, it must meet the following condition:

$$
\sum_{i=1}^{n} w_{i}=1\{i=1,2, \cdots, n\}
$$

Step 4: Ensuring single factor membership matrix

Single-factor evaluation is a method for determining the membership degree. The judgment matrix $R=\left(r_{i j}\right)_{n \times m}(i=1,2, \cdots, n ; j=1,2, \cdots, m)$ is established through the method of expert investigation, grade, statistics, or establishing fuzzy membership function. In the formula above, the $r_{i j}$ is the membership degree of the evaluated object from $u_{i}$ to $v_{j}$. In addition, the $R_{i}=\left(r_{i 1}, r_{i 2}, \cdots, r_{i m}\right)(i=1,2, \cdots, n)$ is the grade fuzzy subset of the evaluation set. Furthermore, the single evaluation matrix $R$ which consists of the grade fuzzy subset is built as follows:

$$
R=\left(\begin{array}{cccc}
r_{11} & r_{12} & \cdots & r_{1 n} \\
r_{21} & r_{22} & \cdots & r_{2 n} \\
\vdots & \vdots & \ddots & \vdots \\
r_{m 1} & r_{m 2} & \cdots & r_{m n}
\end{array}\right)
$$

Step 5: Choose the suitable fuzzy comprehensive operator model

Some function models are listed as follows: maxi-min, max-product, weighted average type and the main factors. All these types are commonly used in fuzzy comprehensive evaluation. Here ${ }_{2}$ we choose lager-take small, $B=W \times R$, that is,

$$
B=\left\{b_{j}=\stackrel{n}{\vee} \vee_{i=1}^{\vee}\left(w_{i} \wedge r_{i j}(j=1,2, \cdots, m)\right\}\right.
$$

After determining $b_{j}$, in accordance with the principle of maximum membership degree, we take the evaluation set element $v_{j}$ which corresponds to the maximum evaluation index $b_{j \max }$ as the result of the evaluation. If $b_{x}=\bigvee_{j=1}^{m} b_{j}$, then the evaluation result level would be $\mathrm{X}$.

Step 6: Multi-factor fuzzy comprehensive evaluation

All the elements of $U$ are divided into several hierarchical levels based on a certain attribute. The single-factor evaluation of each level is the result of the multi-factor comprehensive in the next level. Generally, the calculation is executed from a low level to a high level. In other words, firstly, factors of all levels are calculated respectively with fuzzy comprehensive evaluation, and secondly, the fuzzy 
evaluation is used to calculate the higher level until the evaluation results are finally obtained.

\section{CASE STUdY}

\subsection{HYDROGEOLOGICAL CONDITIONS}

The Bao-Han highway is connected to Baoji and Hanzhong in Shaanxi Province of China. The Wuguanyi highway tunnel is located in the south of Wuguanyi Town of Liuba County, west of the No. 316 national highway. The location of the tunnel is shown in Fig. 2(a). The Wuguanyi Tunnel is composed of two separate tunnels, with the left tunnel being $190 \mathrm{~m}$ long and having a mileage pile number of ZK158+598-ZK158+788) and the right tunnel being $205 \mathrm{~m}$ long and having a mileage pile number of YK158+579-YK158+784.

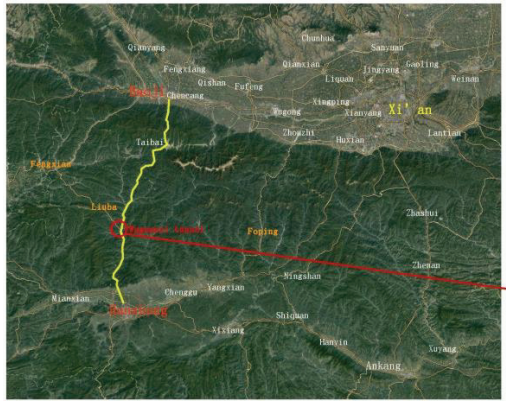

(a)

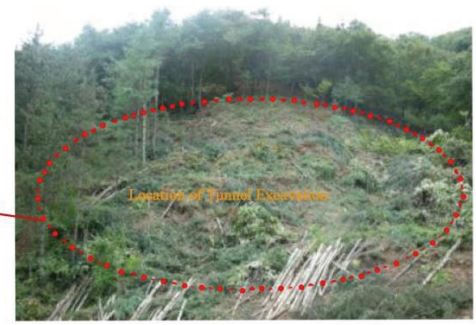

(b)

(a) Location of Wuguanyi highway tunnels

(b) Entrance topography of Wuguanyi Tunnel

Fig. 2. Location and entrance topography of Wuguanyi Tunnel

The entrance of the highway tunnel lies in the valley foot on the right bank of Bao River [see Fig. 2(b)]. The tunnel is perpendicular to the slope surface with no bias. The slope inclination in the tunnel entrance is $357^{\circ}$, and the angle of inclination is $27^{\circ}$. The natural slope is stable and composed of completely weathered granite. The tunnel portal excavation may cause slope instability. The exit of the tunnel is located in the rocky valley slope on the right bank of Bao River. The slope inclination is $178^{\circ}$, and the angle of inclination is $42^{\circ}$. The natural slope is stable with completely weathered granite outcrops. The distance between the left and right tunnels is approximately $26 \mathrm{~m}$. The covering depths on the tunnel portals are lower than $25 \mathrm{~m}$; thus, the portals are the shallow tunnel. The length of the V level surrounding the rock in the left tunnel is $104 \mathrm{~m}$, and that in the right tunnel is $121 \mathrm{~m}$. The portals of the tunnel are all at the $\mathrm{V}$ level of the surrounding rock. The longitudinal profile of the highway tunnel is shown in Fig. 3. 


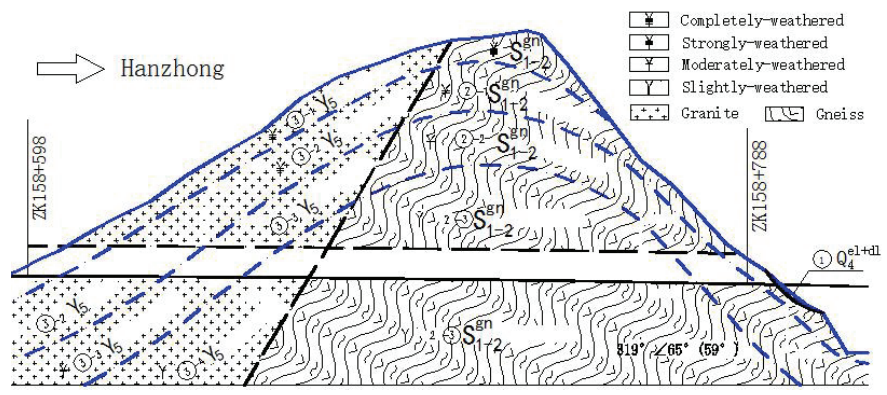

Fig.3. Longitudinal profile of Wuguanyi Tunnel

Groundwater in the tunnel site is bedrock fissure water in submerged condition. Limited by the geological condition, the fracture in the strongly weathered bedrock at the tunnel site area develops, but no groundwater reservoir is formed. The normal water inflow is $34.01 \mathrm{~m}^{3} / \mathrm{d}$, and the maximum water inflow during the rainy season is $60.04 \mathrm{~m}^{3} / \mathrm{d}$. The permeability of the surrounding rock is high. Water quantity and levels are obviously different because of the change of seasons.

\subsection{TUNNEL DESIGN PARAMETERS}

The inner contour section of the tunnel is a three-centred wall section. As the tunnel excavation area is $124.20 \mathrm{~m}^{2}$ and the excavation area is greater than $100 \mathrm{~m}^{2}$, the tunnel is a large-section tunnel. The preliminary support parameters of the tunnel portals are designed as follows: The diameter of the rock bolt is $\Phi 25$; the length is $4.0 \mathrm{~m}$ and the longitudinal seam and circumferential spacing are $1.0 \mathrm{~m} \times 1.0 \mathrm{~m}$. The anchor wall is constructed by a $\Phi 8(20 \mathrm{~cm} \times 20 \mathrm{~cm})$ reinforcing mesh. C25 shotcrete with thickness of $28 \mathrm{~cm}$ is used in the preliminary support structure. The waterproof board is $1.2 \mathrm{~mm}$ thick. The steel frame is $\mathrm{I} 20 \mathrm{H}$ and @ 90 . The diameter of pre-grouting bolt is $\Phi 50$; the length is $4.0 \mathrm{~m}$; the spacing is 0.4 $\mathrm{m}$ and the installation angle is $20^{\circ}-30^{\circ}$. $\mathrm{C} 30$ concrete with a thickness of $60 \mathrm{~cm}$ is used as the secondary lining. The support parameters of the tunnel portals are shown in Fig. 4. To ensure front slope stability, C20 shotcrete with a thickness of $10 \mathrm{~cm}$, the $\Phi 8(20 \mathrm{~cm} \times 20 \mathrm{~cm})$ reinforcing mesh and the mortar bolt $\Phi 25$ with a $4.0 \mathrm{~m}$ length and a distance of $120 \mathrm{~cm} \times 120 \mathrm{~cm}$ are used as the temporary support structure. 


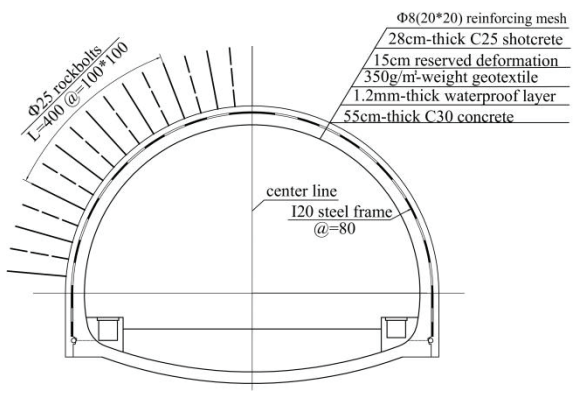

Fig. 4. Support parameters of the tunnel portals

\subsection{PORTAL CONSTRUCTION METHOD}

Tunnel portals are constructed with the center diaphragm construction method (CD method). Pregrouting bolts are constructed to consolidate the surrounding rocks. The tunnel excavation sequence is listed as follows: (1) The upper left part (part I) is excavated, the temporary support structure is installed and the preliminary support structure is completed after the excavation of the upper left part. (2) The lower left part (part II) is excavated, the temporary support structure is installed and the preliminary support structure is completed after the excavation of the lower left part. (3) The upper right part (part III) is excavated, and the temporary support structure is completed after the excavation of the upper right part. (4) The lower right part (part IV) is excavated, and the preliminary support structure is completed after the excavation of the lower right part. (5) The temporary support structure is demolished. (6) The invert arch is installed. (7) The secondary lining is installed when the invert arch is $23 \mathrm{~m}$ long. The abovementioned procedures are repeated until the tunnel is completely constructed. The construction method is shown in Fig. 5.

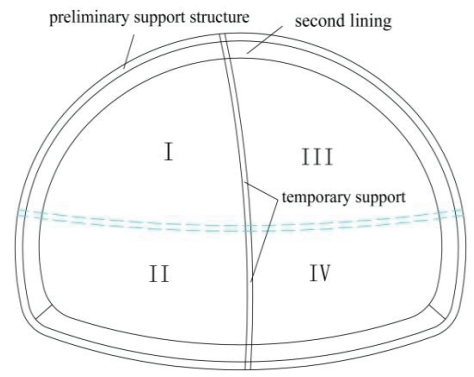

Fig. 5. CD construction method 


\section{RISK EVALUATION AND CONTROL MEASURES}

\subsection{ESTABLISHMENT OF EVALUATION INDEX SYSTEM}

The surrounding rocks of the Wuguanyi Tunnel portals are at the V level. Moreover, the depth of the tunnel portal section is less than $36 \mathrm{~m}$, and the tunnel is a shallow tunnel. Forming a stable balance arch is difficult when the covering depth of the rock and soil mass is thin. Excavation disturbance and rainfall are likely to cause the instability and the collapse of the surrounding rocks in the portal section, especially for the broken surrounding rock. On the basis of the abovementioned analysis, tunnel face instability, slope instability, large deformation and water bursting are considered as the construction risks. Thus, the first-grade indices $C=\left\{C_{1}, C_{2}, \cdots, C_{n}\right\}$ of the construction risk for tunnel portals are established through expert investigation. The abovementioned four types of risk are caused by the second-grade index $P=\left\{P_{1}, P_{2}, \cdots, P_{n}\right\}$ (the covering depth of the portal section, cross-section size, surrounding rock conditions, support parameters, construction method, rainfall and groundwater). AHP is established in Fig. 6. The importance of risk factors is compared by the questionnaire, which is combined with system engineering theory. The importance of the risk factor comparison is shown in Table 1.

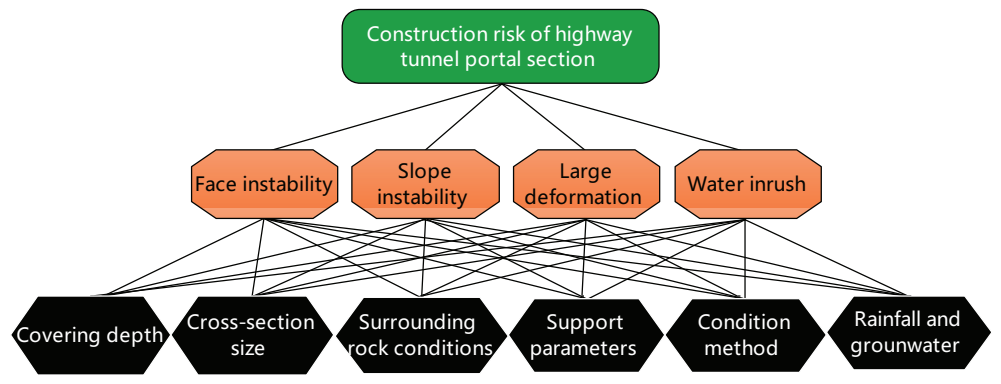

Fig. 6. Horizontal structure of construction risk in tunnel portal section

Table 1 Importance of risk factors comparison

\begin{tabular}{|c|c|c|c|c|c|c|}
\hline \multirow[b]{2}{*}{$\begin{array}{c}\text { Construction } \\
\text { risk }\end{array}$} & \multicolumn{6}{|c|}{ Importance of risk factor } \\
\hline & $\begin{array}{c}\text { Covering } \\
\text { depth of portal } \\
\text { section } \\
\text { P1 }\end{array}$ & $\begin{array}{c}\text { Cross- } \\
\text { section sizes } \\
\text { P2 }\end{array}$ & $\begin{array}{l}\text { Surrounding } \\
\text { rock } \\
\text { conditions } \\
\text { P3 }\end{array}$ & $\begin{array}{c}\text { Support } \\
\text { parameters } \\
\text { P4 }\end{array}$ & $\begin{array}{l}\text { Constructi } \\
\text { on } \\
\text { methods } \\
\text { P5 }\end{array}$ & $\begin{array}{c}\text { Rainfall and } \\
\text { groundwater } \\
\text { P6 }\end{array}$ \\
\hline Tunnel face & small & general & maximum & less & large & minimum \\
\hline
\end{tabular}




\begin{tabular}{|c|c|c|c|c|c|c|}
\hline instability & & & & & & \\
\hline $\mathrm{C} 1$ & & & & & & \\
\hline $\begin{array}{c}\text { Slope } \\
\text { instability } \\
\text { C2 }\end{array}$ & large & minimum & maximum & small & less & general \\
\hline $\begin{array}{c}\text { Great } \\
\text { deformation } \\
\text { C3 }\end{array}$ & large & general & maximum & minimum & small & less \\
\hline $\begin{array}{c}\text { Burst water } \\
\text { C4 }\end{array}$ & less & less & maximum & minimum & general & large \\
\hline
\end{tabular}

The results of the importance of risk factors for each risk are compared and listed as a 6-order to calculate the maximum eigenvalue; consistency is examined thereafter [21]. The random consistency index $(R I)$ is shown in Table 2.

Table 2 Random consistency index $(R I)$

\begin{tabular}{ccccccccc}
\hline$n$ & 3 & 4 & 5 & 6 & 7 & 8 & 9 & 10 \\
\hline$R I$ & 0.52 & 0.89 & 1.11 & 1.25 & 1.35 & 1.40 & 1.45 & 1.49 \\
\hline
\end{tabular}

\subsection{IDENTIFICATION OF EVALUATION SETS}

The evaluation set is a language description of the evaluation index at all levels. It is a set of reviews given by the reviewers for each evaluation index. This evaluation model considers the influence of various risks on the whole tunnel construction project and finally divides the comments into five grades, namely, $V=\left\{v_{1}, v_{2}, v_{3}, v_{4}, v_{5}\right\}=($ level 1, level 2, level 3, level 4, level 5) $=($ less risk, low risk, general risk, high risk, higher risk).

\subsection{WEIGHT ANALYSIS OF RISK FACTORS}

The relative weight coefficients are calculated by AHP according to the abovementioned importance of risk factor comparison corresponding to each construction risk. The relative weight coefficients are described as follows:

$$
W=\left\{w_{1}, w_{2}, \cdots, w_{n}\right\}
$$

Meanwhile, the single hierarchical arrangement is obtained by $W$, and the total ranking results are shown in Table 3.

Table 3 Total ranking results of risk factor weight

Risk factors Risk of construction




\begin{tabular}{|c|c|c|c|c|c|}
\hline & $\mathrm{C} 1$ & $\mathrm{C} 2$ & C3 & $\mathrm{C} 4$ & Total ranking \\
\hline $\mathrm{P} 1$ & 0.0366 & 0.2102 & 0.2102 & 0.0549 & 0.1116 \\
\hline $\mathrm{P} 2$ & 0.1829 & 0.0210 & 0.0701 & 0.0549 & 0.1214 \\
\hline P3 & 0.3659 & 0.6305 & 0.6305 & 0.4396 & 0.4825 \\
\hline P4 & 0.1098 & 0.0263 & 0.0210 & 0.0110 & 0.0676 \\
\hline P5 & 0.2927 & 0.0420 & 0.0263 & 0.1648 & 0.1748 \\
\hline P6 & 0.0122 & 0.0701 & 0.0420 & 0.2747 & 0.0422 \\
\hline
\end{tabular}

As listed in Table 3, the largest relative weight coefficient is 0.4825 , which indicates the surrounding rock conditions. Similarly, the smallest relative weight coefficient indicates rainfall and groundwater. In accordance with the results, the factors in the Wuguanyi highway tunnel portal section are ordered according to importance as follows: surrounding rock conditions, construction methods, section sizes, cover depth of portals, support parameters and rainfall and groundwater.

\subsection{FUZZY COMPREHENSIVE EVALUATION}

Ensuring membership degree of risk factor is an important task of fuzzy evaluation. Once the risk evaluation index system and the weight of index in the Wuguanyi Tunnel portal section are obtained, 10 experts are invited as decision makers to give their own judgements for the second-grade index factors. Thereafter, the votes on the independent index from the 10 experts in each level are collected, that is, the index membership in each level, which is shown in Table 4.

Table 4 Membership matrix

\begin{tabular}{ccccccc}
\hline Risk factors & Weight & Less low risk & Low risk & General risk & Higher risk & High risk \\
\hline P1 & 0.1116 & 1 & 9 & 0 & 0 & 0 \\
P2 & 0.1214 & 0 & 2 & 8 & 0 & 0 \\
P3 & 0.4825 & 0 & 0 & 0 & 10 & 0 \\
P4 & 0.0676 & 0 & 10 & 0 & 0 & 0 \\
P5 & 0.1748 & 0 & 0 & 9 & 1 & 0 \\
P6 & 0.0422 & 0 & 3 & 7 & 0 & 0 \\
\hline
\end{tabular}

The risk grade evaluation matrix $R$ and the risk factor comprehensive weights $W$ are shown as follows:

$$
R=\left(r_{i j}\right)_{n \times m}(i=1,2, \cdots, n ; j=1,2, \cdots, m)
$$




$$
\begin{aligned}
& R=\left[\begin{array}{c}
R 1 \\
\vdots \\
R_{n}
\end{array}\right]=\left[\begin{array}{ccc}
r_{11} & \cdots & r_{1 n} \\
\vdots & \ddots & \vdots \\
r_{m 1} & \cdots & r_{m n}
\end{array}\right]=\left[\begin{array}{ccccc}
0.1 & 0.9 & 0 & 0 & 0 \\
0 & 0.2 & 0.8 & 0 & 0 \\
0 & 0 & 0 & 1 & 0 \\
0 & 1 & 0 & 0 & 0 \\
0 & 0 & 0.9 & 0.1 & 0 \\
0 & 0.3 & 0.7 & 0 & 0
\end{array}\right] \\
& W=\{0.1166,0.1214,0.4825,0.0676,0.1748,0.0422\}
\end{aligned}
$$

Fuzzy evaluation result $B$ is obtained according to the evaluation membership matrix $R$ and the comprehensive weight coefficients $W$ of the risk factors. The fuzzy comprehensive evaluation matrix is shown as follows:

$$
\begin{gathered}
B=W^{T} \cdot R=\left(w_{1} \cdots w_{n}\right) \cdot\left[\begin{array}{ccc}
r_{11} & \cdots & r_{1 n} \\
\vdots & \ddots & \vdots \\
r_{m 1} & \cdots & r_{m n}
\end{array}\right] \\
B=\left[\begin{array}{l}
0.1116 \\
0.1214 \\
0.4825 \\
0.0676 \\
0.1748 \\
0.0422
\end{array}\right]^{T}\left[\begin{array}{ccccc}
0.1 & 0.9 & 0 & 0 & 0 \\
0 & 0.2 & 0.8 & 0 & 0 \\
0 & 0 & 0 & 1 & 0 \\
0 & 1 & 0 & 0 & 0 \\
0 & 0 & 0.9 & 0.1 & 0 \\
0 & 0.3 & 0.7 & 0 & 0
\end{array}\right]
\end{gathered}
$$

Taking the evaluation element $v_{j}$, which corresponds to the maximum evaluation index $b_{j \max }$, as the result according to the principle of membership degree, the maximum evaluation index $b_{j \max }$ is 0.4999. Therefore, the risk probability level of the construction in Wuguanyi highway tunnel portal section is grade IV, which belongs to high risk, and risk control measures should be applied to the construction to ensure the stability of the tunnel.

\subsection{RISK CONTROL MEASURES}

The risk probability level of the construction for Wuguanyi highway tunnel portals is grade IV, which indicates high risk, and the risk factors are ordered according to importance as follows: surrounding rock conditions, construction methods, section sizes, covering depth of portals, support parameters and rainfall and groundwater. Hence, the construction method, pre-support measures and dynamic monitoring of the tunnel are important for ensuring construction safety. In view of the risk assessment results, the risk control measures are proposed as follows:

(1) Setting the long pipe roof. Ensuring the stability of the tunnel entrance is difficult because of the 
poor quality of the rock mass, the thinner cover depth and rainfall in Wuguanyi Tunnel. Hence, the presupport measures should be improved before the excavation of the tunnel. Actually, the pipe roof has a good effect as a pre-support measure in the construction of the tunnel portals. A $30 \mathrm{~m}$ long pipe roof, which consists of a total of 44 seamless steel pipes $(\Phi 108 \times 6 \mathrm{~mm})$ with a construction scope of $2 \times 57^{\circ}$, is suggested as a pre-support measure of the tunnel entrance on the basis of the abovementioned analysis. Single pipe sections are 3 or $6 \mathrm{~m}$ in length and are connected at the joints by $150 \mathrm{~mm}$ long threaded sections. With the use of the umbrella arch as a guide wall, the pipe roof is constructed along the outer contour line of the open cut. Photographs of the design and construction of the pipe roof are shown in

Figs. 7 and 8 .

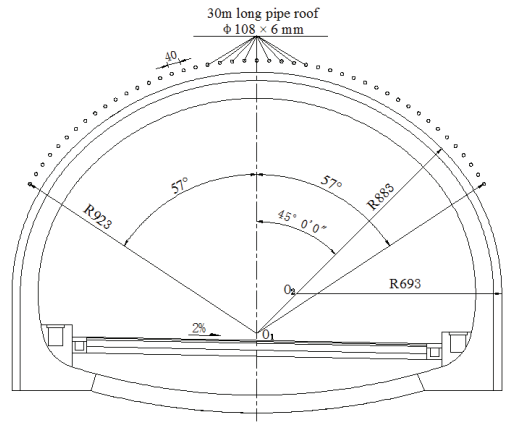

Fig. 7. Design of pipe roof in the tunnel portal

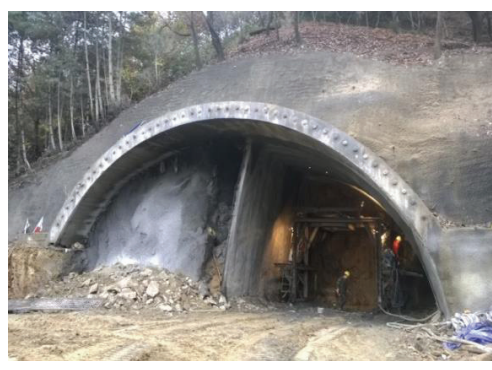

Fig. 8. Construction condition in the tunnel portal

(2) Strengthening the supporting parameters. The supporting parameters are important in avoiding tunnel face instability and great deformation of the tunnel portals. Therefore, the diameter of the rock bolt is improved to $\Phi 28$, and the length is increased to $4.5 \mathrm{~m}$. The $\mathrm{I} 20 \mathrm{~b} \mathrm{H}$ steel frame is adopted, and the length of the pre-grouting bolt is added to $5.0 \mathrm{~m}$. The improved construction method is shown in Fig. 8 .

(3) Optimising the construction methods. The control of the construction process is also a key factor. The control measures include the following: the excavation footage is no greater than $3.0 \mathrm{~m}$, and the distances between different excavation parts are maintained at $9.0 \mathrm{~m}$ to maintain tunnel stability. Meanwhile, the anchorage, primary lining and invert arch are constructed in time. When the invert arch is $12 \mathrm{~m}$ long, the secondary lining is installed. The blasting charge should be strictly controlled in the portal section to reduce the influence of the blasting excavation. Finally, the dynamic monitoring of tunnel deformation should be strengthened during the construction process. 


\section{DEFORMATION MONITORING RESULTS AND ANALYSIS}

In order to monitor the stability of Wuguanyi Tunnel during the construction process, 17 monitoring sections of the settlement deformation of the crown are selected, including seven monitoring sections of the left tunnel and eleven monitoring sections of the right tunnel. During the monitoring process, four settlement monitoring points were arranged at the vault, and the reflective sheets were set at the measuring points. The monitoring data was measured by TOPCON GTS-721 total station. The monitoring program is shown in Figs 9and 10.

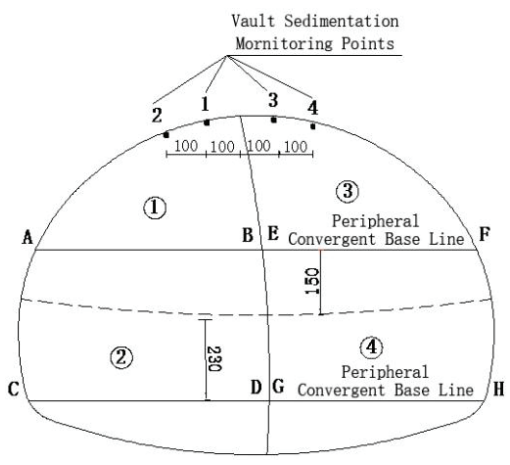

Fig.9. Monitoring program

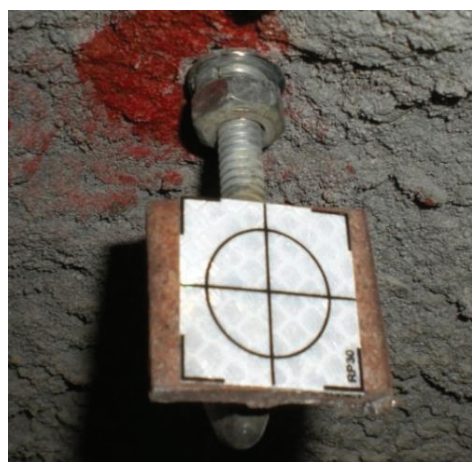

Fig.10. Measuring point arrangement

One section of left tunnel and one section of right tunnel which belonging to the portal sections are selected as monitoring sections. The mileage stakes are ZK158 +616.8 and YK158+613.5. The crown settlement monitoring of the tunnel portal work began in December 2014. The monitoring process will be carried out immediately when the excavation of first part starts, and it will not stop until the tunnel construction is completed.

The crown settlement monitoring value of two selected sections is recorded as temporal curve. The temporal curves are shown in Figs 11 and 12.

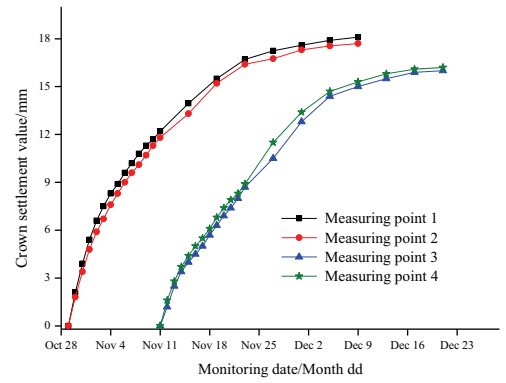


Fig.11. ZK158 + 616.8 section temporal curves of the crown settlement

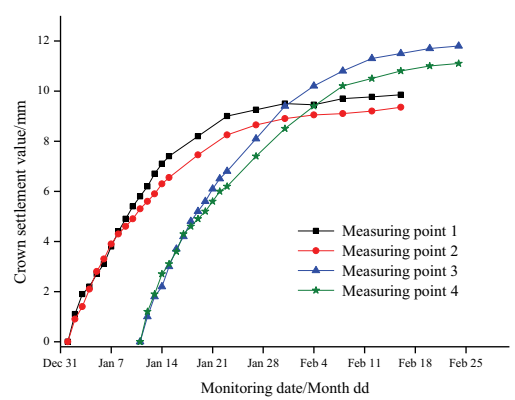

Fig.12. YK158 + 613.5 section temporal curves of the crown settlement

The data of two monitoring sections are shown in Table 5 .

Table 5 Settlement data of monitoring sections

\begin{tabular}{cccccc}
\hline \multirow{2}{*}{$\begin{array}{c}\text { Monitoring } \\
\text { section }\end{array}$} & Monitoring data & \multicolumn{3}{c}{ The final value of the crown settlement $(\mathrm{mm})$} \\
\cline { 3 - 6 } & & point 1 & point 2 & point 3 & point 4 \\
\hline ZK158+616.8 & $\begin{array}{c}2014 / 10 / 29 \sim 12 / \\
21\end{array}$ & 19.13 & 18.64 & 20.48 & 21.13 \\
\hline YK158+613.5 & $\begin{array}{c}2015 / 01 / 01 \sim 02 / \\
24\end{array}$ & 14.92 & 14.24 & 16.25 & 15.44 \\
\hline
\end{tabular}

Table 5 shows the settlement values of two portals sections ZK158 +616.8 and YK158 +613.5 . Among them, the maximum value of ZK158 +616.8 section is $18.12 \mathrm{~mm}$; the maximum value of YK158 +613.5 section is $11.85 \mathrm{~mm}$. Therefore, the settlement values of the two sections are very small and less than the required value which is determined by the Chinese Specifications. On the basis of the monitoring results, these risk control measures such as setting long pipe roof, strengthening supporting parameters and optimizing construction methods play the important role in controlling the crown settlement of tunnels. These risk control measures are reasonable and reliable to control the construction risk of the tunnel portal.

\section{Conclusion}

Slope instability, rock falls, tunnel face instability and large deformation of tunnels may arise during the construction of tunnel portals because of the poor quality of rock masses, the thinner covering depth, rainfall and underground water and other factors. FAHP, formed by combining fuzzy mathematics theory and AHP, is proposed to identify the importance of the influencing factors and the risk level for tunnel portals in this study. Meanwhile, the risk control 
measures are presented for Wuguanyi Tunnel. The main conclusions are listed as follows:

(1) Fuzzy judgments are used instead of the usual 1-9 fundamental scale in making pairwise comparisons according to the weakness of AHP in assessing the relative importance weights of the various criteria. Moreover, FAHP is proposed by combining fuzzy mathematics theory and AHP.

(2) FAHP is applied for the Wuguanyi highway tunnel. The four kinds of risks are identified during the construction of the tunnel portals, and the risk factors which cause the four types of risks are determined. Firstly, the fuzzy AHP method is used to establish the construction risk hierarchy of the Wuguanyi highway tunnel portal section. Secondly, the comprehensive weights of the risk factors are analysed. The risk factors are ordered according to importance as follows: surrounding rock conditions, construction methods, section sizes, cover depth of portals, support parameters and rainfall and groundwater. Finally, the risk probability level of Wuguanyi highway tunnel portals is determined as grade IV on the basis of the abovementioned analysis.

(3) The following risk control measures during the construction of Wuguanyi Tunnel portals are suggested: Long pipe roof reinforcement is proposed to consolidate the surrounding rocks in the tunnel portal section. The supporting parameters, such as the rock bolt, steel frame and pre-grouting bolt, are strengthened based on the actual conditions. The excavation footage, the distance between different excavation parts and the blasting charge should be strictly controlled during the construction process.

(4) The settlement values of two tunnel portal sections are small and less than the required value which is determined by the Chinese Specifications according to the monitoring results. The monitoring results shows that the risk control measures are reasonable and reliable to control the construction risk of the tunnel portal. 
Acknowledgments

This research was financially supported by the National Natural Science Foundation of China (Grant No. 51408054 sponsored), the Natural Science Foundation (2017JM5136) by the Science and Technology Department of Shaanxi Province, the Housing and Urban-Rural Construction Foundation (2017-K55) by the Housing and Urban-Rural Department of Shaanxi Province, the Scientific Research Program (KLTLR-Y14-15) for Technology of Highway Construction and Maintenance Technology of National Transportation Industry Key Laboratory and the Research Program (XAGDXJJ16003) sponsored by Xi'an Technological University.

\section{REFERENCES}

1. F. Ye, C.He, S. M.Wang, J. L. Zhang. "Landscape design of mountain highway tunnel portals in China”, Tunnelling and Underground Space Technology, 29, 52-68, 2012.

2. D. Peila, S. Pelizza. "Criteria for technical and environmental design of tunnel portals", Tunnelling and Underground Space Technology, 17, 335-340, 2002.

3. M. Li, "Research of Landscape Design on the Entrance of Highway Tunnel", Master Dissertation, Kunming University of Science and Technology, Kunming, 2008 (in Chinese).

4. Özgür Satıcıa, Bahtiyar Ünverba. "Assessment of tunnel portal stability at jointed rock mass: A comparative case study”, Computers and Geotechnics, 64, 72-82, 2014.

5. Nezarat Hamidreza, Sereshki Farhang Ataei Mohammad. "Ranking of Geological risks in Mechanized Tunneling by Using Fuzzy Analytical Hierarcy Process (FAHP).” Tunnelling and Underground Space Technology, 50, 358-364, 2015.

6. M. Ersoy. "The role of occupational safety measures on reducing accidents in marble quarries of Iscehisar region." Safety Science, 57, 293-302, 2013.

7. A. Badri, S Nadeau, A Gbodossou. "A new practical approach to risk management for underground mining project in Quebec." Journal of Loss Prevention in the Process Industries, 26, 1145-1158, 2013

8. K A S Al-Harbi. “Application of the AHP in project management.” International Journal of Project Management, 19, 19-27, 2001.

9. C M Tam, T K L Tong, G W C Chiu. "Comparing non-structural fuzzy decision support system and analytical hierarchy process in decision making for construction problems." European Journal of Operational Research, 174, 1317-1324, 2006

10. Q. X. Wang, H. Wang, Z. Q. Qi. "An application of nonlinear fuzzy analytic hierarchy process in safety evaluation of coal mine." Safety Science, 86, 78-87, 2016.

11. K Meng Tay, C Peng Lim. "Fuzzy FMEA with a guided rules reduction system for prioritization of failures.” International Journal Quality \& Reliability Management, 23, 10471066, 2006.

12. E. Triantaphyllou, S. Mann, "An evaluation of the eigenvalue approach for determining the 
membership values in fuzzy sets," Fuzzy Sets and Systems, 35, 295-301, 1990.

13. G. Lakoff, Hedges. "a study in meaning criteria and the logic of fuzzy concepts." Journal of Philosophical Logic, 2, 234-281, 1977.

14. Laarhoven, Van, P J M Pedrycz. “A fuzzy extension of Saaty's priority theory.” Fuzzy Set and Systems, 11, 229-241, 1983.

15. D Y Chang. "Applications of the extent analysis method on fuzzy AHP.” European Journal of Operational Research, 95, 649-655, 1996.

16. B Asady. "The revised method of ranking LR fuzzy number based on deviation degree." Expert Systems with Applications, 37, 5056-5060, 2010.

17. Y K Zhu. "Fuzzy analytic hierarchy process: Fallacy of the popular methods." European Journal of Operational Research, 239, 209-217, 2014.

18. Li F, Phoon K, Du X, et al. "Improved AHP method and its application in risk identification." Journal of Construction Engineering and Management, 139(3), 312-320, 2013.

19. B. S. Liang, D. L. Cao. "Fuzzy mathematics and application." Beijing: Science Press, 2007. (in Chinese)

20. Y. X. Zhao, W. Y. Xu. "Risk assessment of TBM construction for tunnels based on AHP and fuzzy synthetic evaluation.” Rock and Soil Mechanics, 30(30), 793-798, 2009. (in Chinese)

21. T.L. Saaty, L.G. "Vargas, Models, Methods, Concepts \& Applications of the Analytic Hierarchy Process.” Springer, 2012.

\section{LIST OF FIGURES AND TABLES:}

Fig. 1. Flow diagram of the proposed method

Table 1 Importance of risk factors comparison

Fig. 2. Location and entrance topography of Wuguanyi Tunnel

Table 2 Random consistency index (RI)

Fig.3. Longitudinal profile of Wuguanyi Tunnel

Table 3 Total ranking results of risk factor weight

Fig. 4. Support parameters of the tunnel portals

Table 4 Membership matrix

Fig. 5. CD construction method

Table 5 Settlement data of monitoring sections

Fig. 6. Horizontal structure of construction risk in tunnel portal section 
Fig. 7. Design of pipe roof in the tunnel portal

Fig. 8. Construction condition in the tunnel portal

Fig.9. Monitoring program

Fig.10. Measuring point arrangement

Fig.11. ZK158 + 616.8 section temporal curves of the crown settlement

Fig.12. YK158 +613.5 section temporal curves of the crown settlement 